\title{
Real-time monitoring of leakage current on insulating cross-arms in relation to local weather conditions
}

DOI:

10.1109/EIC.2013.6554275

Link to publication record in Manchester Research Explorer

\section{Citation for published version (APA):}

Zachariades, C., Rowland, S. M., \& Cotton, I. (2013). Real-time monitoring of leakage current on insulating crossarms in relation to local weather conditions. In 2013 IEEE Electrical Insulation Conference, EIC 2013/IEEE Electr. Insul. Conf., EIC (pp. 397-401). https://doi.org/10.1109/EIC.2013.6554275

\section{Published in:}

2013 IEEE Electrical Insulation Conference, EIC 2013|IEEE Electr. Insul. Conf., EIC

\section{Citing this paper}

Please note that where the full-text provided on Manchester Research Explorer is the Author Accepted Manuscript or Proof version this may differ from the final Published version. If citing, it is advised that you check and use the publisher's definitive version.

\section{General rights}

Copyright and moral rights for the publications made accessible in the Research Explorer are retained by the authors and/or other copyright owners and it is a condition of accessing publications that users recognise and abide by the legal requirements associated with these rights.

\section{Takedown policy}

If you believe that this document breaches copyright please refer to the University of Manchester's Takedown Procedures [http://man.ac.uk/04Y6Bo] or contact uml.scholarlycommunications@manchester.ac.uk providing relevant details, so we can investigate your claim.

\section{OPEN ACCESS}




\title{
Real-time Monitoring of Leakage Current on Insulating Cross-arms in Relation to Local Weather Conditions
}

\author{
C. Zachariades, S. M. Rowland, I. Cotton, \\ School of Electrical and Electronic Engineering \\ The University of Manchester \\ Manchester, M13 9PL, \\ United Kingdom \\ christos.zachariades@manchester.ac.uk
}

\begin{abstract}
Two insulating cross-arms have been installed within a trial site near the coast of Northeast Scotland, energised at $231 \mathrm{kV}$. The trial aims to observe the electrical behaviour of the cross-arm by monitoring in real time the leakage current of the insulating members. The weather monitoring equipment installed at the site records wind speed and direction, precipitation, atmospheric pressure, temperature, relative humidity, visibility and solar irradiance. The instrumentation is complemented by cameras that provide visual verification regarding the conditions at the site. The results from the trial during June 2012 show that the cross-arm performs according to design expectations. The leakage current profile of the novel compression insulators is similar to that of the industry standard tension insulators. A relative humidity threshold of $90 \%$ has been identified which if exceeded, results in increased leakage current activity. Additionally it has been found that the prevailing wind affects the south facing cross-arm more than the west facing one. Also, the effects of precipitation have been found to be more prominent on the tension members.
\end{abstract}

Cross-arm; composite; insulator; transmission line, NCI, test facility, leakage current, monitoring system.

\section{INTRODUCTION}

To meet the continuously increasing electricity demand, which is pushing many transmission corridors closer to their limits, the power sector is seeking solutions for improving the power transfer capabilities of existing infrastructure. To address this issue an insulating cross-arm has been developed (Fig. 1) that can be retrofitted on existing towers enabling the uprating of lines to higher voltages. The technology is not only more economical but also negates the environmental impact associated with erecting a new line and minimises potential planning issues. It can contribute to the reduction of electromagnetic radiation at ground level and make towers less obtrusive [1].

The insulating cross-arm consists of four members, two of which are standard tension composite insulators. Utilising a combination of innovative design, and proven materials and manufacturing methods, the main feature of the cross-arm is its compressive elements. Their distinctive cross-sectional shape makes them lighter than cylindrical alternatives while providing high compressive strength as well as resistance to bending and buckling. While mechanically their performance has been proven both in laboratory tests and during a two year trial installation [2], the departure from traditional designs coupled with limited service experience requires verification of the electrical performance of the novel insulators and the reliability of the cross-arm in general.

To alleviate any concerns and prepare for deployment of the cross-arm on the network, a live test site was commissioned in north-east Scotland in May 2012. The main aims of the trial are:

- To observe the electrical behaviour of the cross-arm and how it changes in relation to the environmental conditions.

- To compare the performance of the novel compression insulators with that of the 'traditional' tension insulators.

- To identify aspects of the cross-arm that can be improved further (insulator profile, grading devices).

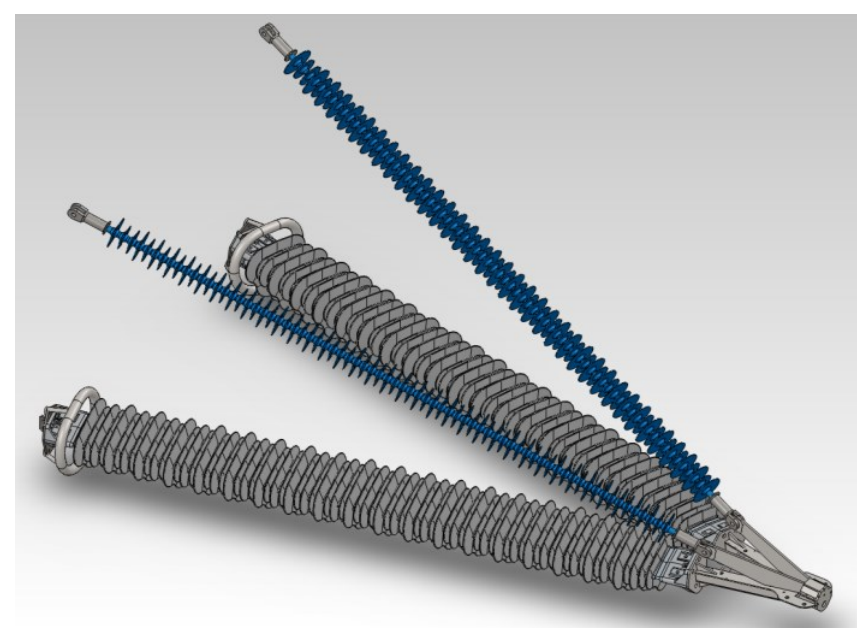

Figure 1. The Insulating Cross-arm 


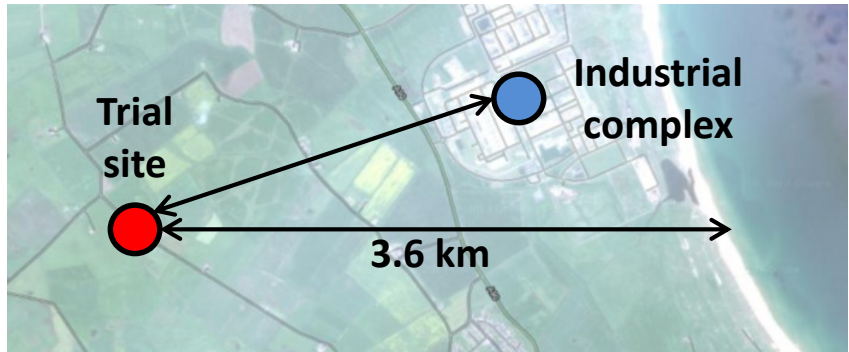

Figure 2. Trial site location

In this paper, the trial site and the instrumentation are described in brief. Furthermore, the first results from the trial are presented. Specifically, two short periods of leakage current activity from June 2012 are examined in detail. The discussion that follows explains the observations and links the leakage current patterns with the local weather conditions, site-specific factors and differences between the insulating members.

\section{THE TRIAL SITE}

The substation in which the trial is taking place is situated $3.6 \mathrm{~km}$ from the coast. In the East, there is also a large industrial complex (Fig. 2). The site provides an onerous environment for long-term measurements.

Two insulating cross-arms have been installed on a bespoke lattice tower. One cross-arm is facing south while the other is facing west. An $8 \mathrm{~m}$ span of conductor connects their conductor attachment points. A $50 \mathrm{kVA}$ transformer provides $231 \mathrm{kV}$ phase-to-ground which is the equivalent of $400 \mathrm{kV}$ phase-to-phase that the cross-arms will experience in service (Fig. 3).

\section{INSTRUMENTATION}

The primary cause of polymeric insulator failure nowadays is surface degradation which is affected by the local environmental conditions [3]. The hydrophobic properties of the material may diminish over time allowing the formation of continuous water paths when the insulator becomes wet [4].

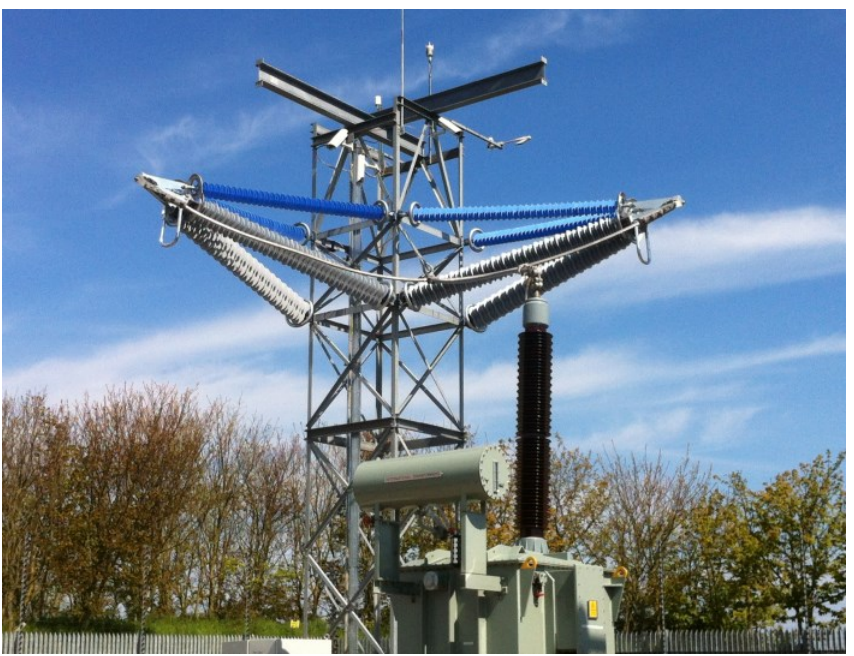

Figure 3. Live trial site
Eventually, increased leakage current flow and arcing activity could lead to flashover [5].

As one of the few parameters that can practically be measured, leakage current has been associated with insulator ageing, performance and reliability [6]. For the purposes of this trial, the insulators that comprise the cross-arm are isolated from the tower using insulating brackets to enable the measurement of leakage current from the individual members. Furthermore, a weather transmitter, a 'present weather' detector (fog sensor) and a pyranometer record the following weather parameters:

- $\quad$ wind speed

- $\quad$ wind direction

- precipitation

- atmospheric pressure

- temperature

- relative humidity

- visibility

- solar irradiance

To complement the monitoring instruments, four cameras overlook the cross-arms in order to capture pollution accumulation, possible changes in hydrophobicity as well as snow and ice accretion patterns. All of the recordings are synchronised and time-stamped. Fig. 4 shows a block diagram of the instrumentation system. More details regarding the monitoring equipment and the protection system employed at the site can be found in [7].

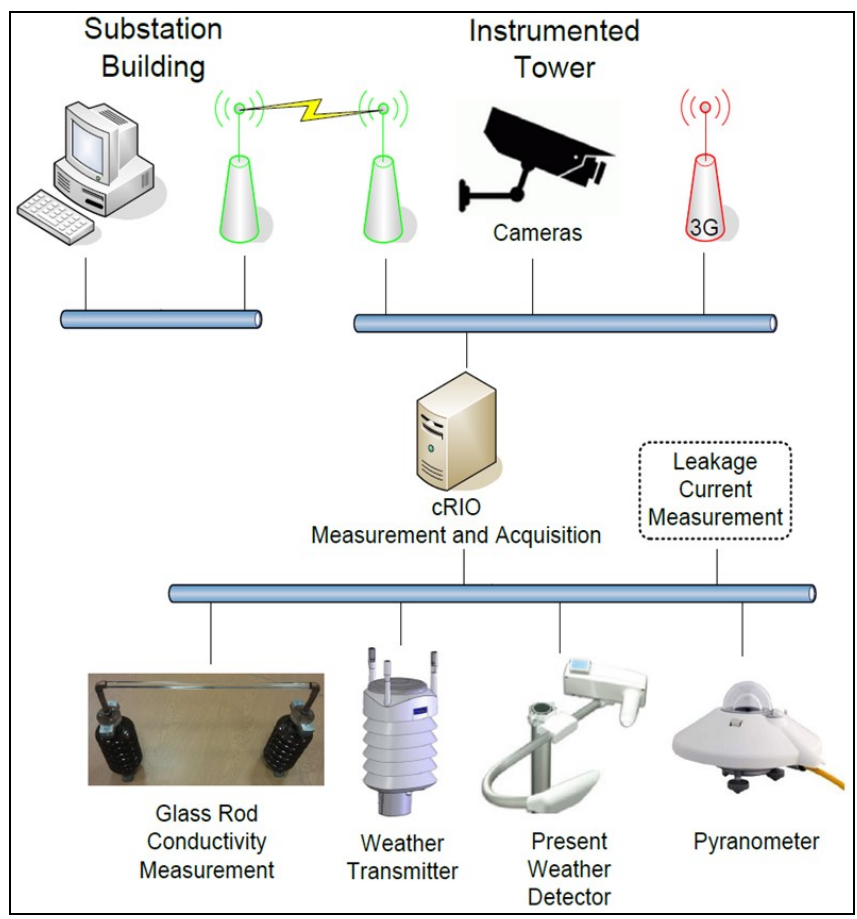

Figure 4. Trial site instrumentation system 


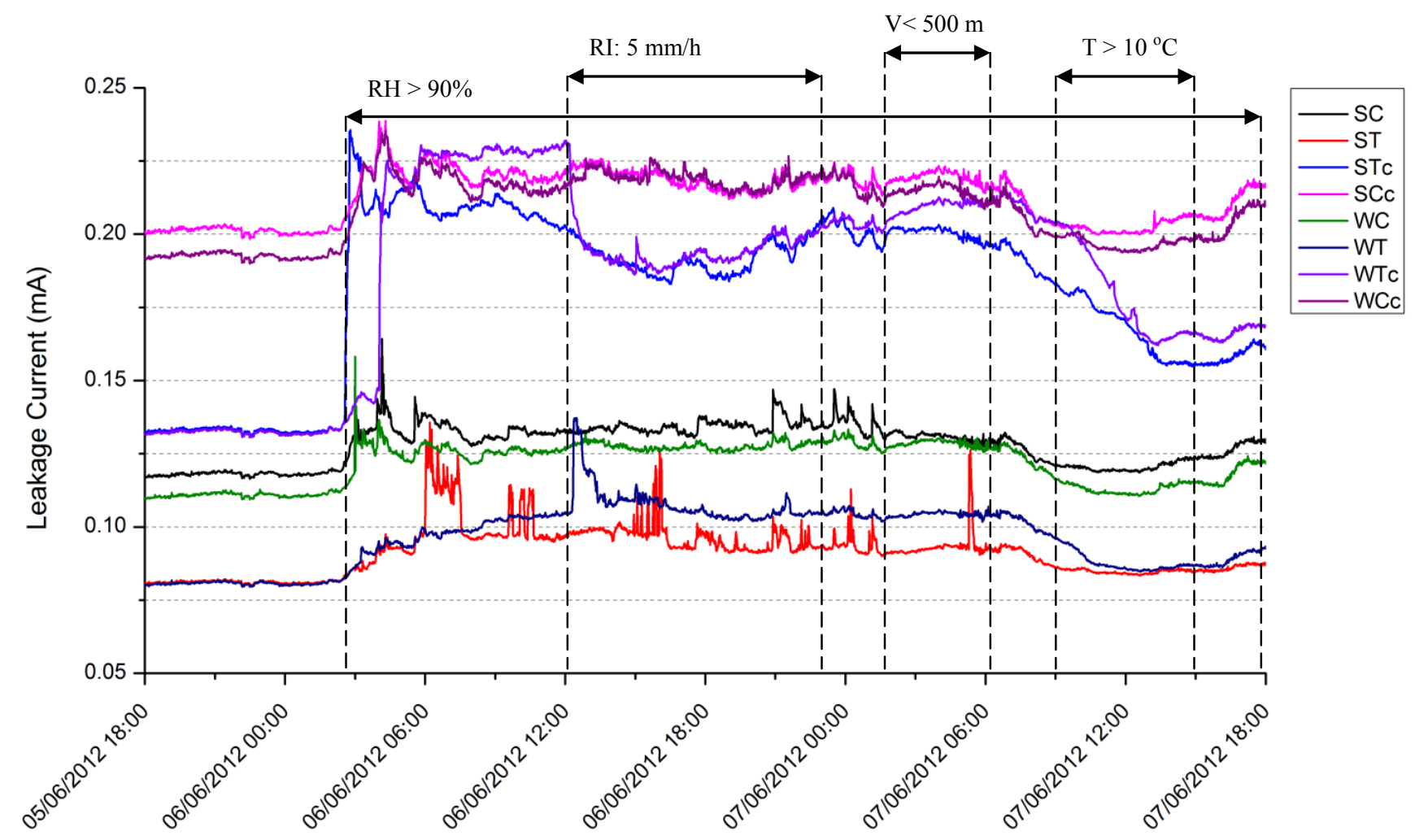

Figure 5. Leakage current $-5^{\text {th }}$ to $7^{\text {th }}$ of June 2012

\section{RESULTS}

The subsequent sections describe two periods of typical leakage current activity during June 2012. The leakage current waveforms from the individual members are labelled based on the direction the cross-arm is facing, the type of insulator and the proximity to the conductor as follows:

SC: South Compression

ST: South Tension

STc: South Tension near conductor

SCc: South Compression near conductor

WC: West Compression

WT: West Tension

WTc: West Tension near conductor

WCc: West Compression near conductor

Additionally the abbreviations below are used:

RH: Relative Humidity

RI: Rainfall Intensity (average)

V: Visibility

\section{T: $\quad$ Temperature}

\section{A. $5^{\text {th }}$ to $7^{\text {th }}$ of June 2012}

Fig. 5 shows the leakage current activity on the two crossarms during a two day period starting at 18:00 on the $5^{\text {th }}$ of June and ending at 18:00 on the $7^{\text {th }}$ of June. The days preceding this period were dry, with humidity ranging between $45 \%$ and $80 \%$, and easterly wind which persists for the entire period. The currents recorded in this period are steady. They have different absolute values because the individual insulator elements are all in a different geometric position relative to the conductor and each other. The compression elements also have a wider body than the tension elements.

At approximately $03: 00$ on the $5^{\text {th }}$, the humidity level exceeds $90 \%$ which causes the leakage current on all insulators to rise above their base value. The increase is higher on the tension members. At 12:00 on the $6^{\text {th }}$, a spell of rainfall reduces the leakage current magnitude especially on the tension insulators. A brief period of fog starting at 02:00 on the $7^{\text {th }}$, indicated by the low visibility registered on the fog sensor, contributes to the prolongation of the higher leakage current activity. By $06: 00$ on the $7^{\text {th }}$, the fog subsides while the temperature starts to rise resulting on the drying of the

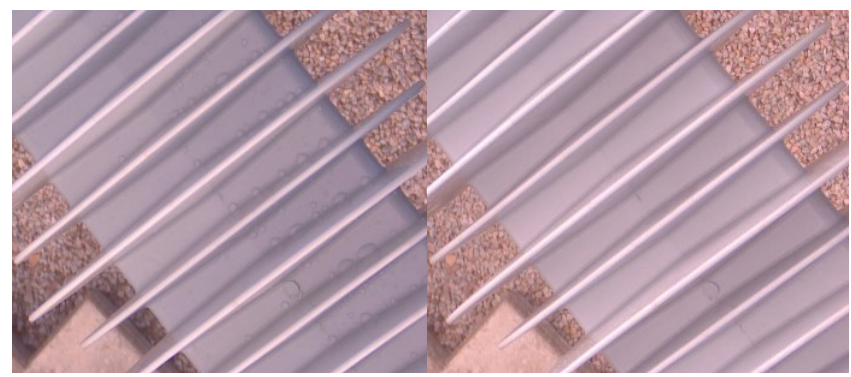

Figure 6. WCc at 07:00 (left) and 12:00 (right) on the $7^{\text {th }}$ June 2012 


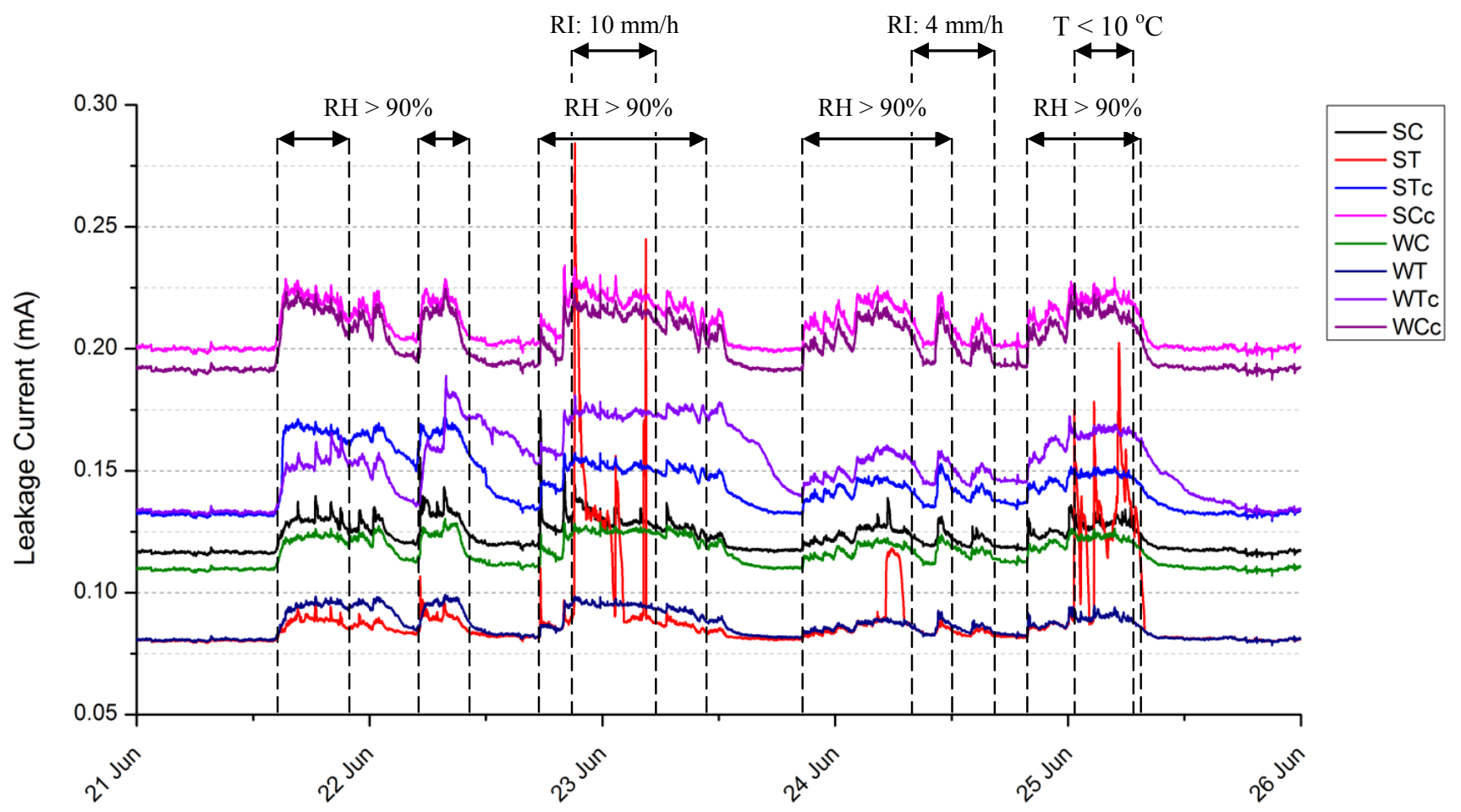

Figure 7. Leakage current $-21^{\text {st }}$ to $26^{\text {th }}$ of June 2012

insulators and the reduction of leakage current. This is corroborated by the camera images. Fig. 6 shows the WCc member at 07:00 with moisture in the form of water droplets still on its surface which by 12:00 has completely evaporated.

\section{B. $21^{\text {st }}$ to $26^{\text {th }}$ of June 2012}

Fig. 7 shows a period of leakage current activity spanning several days towards the end of June 2012. The wind before the $21^{\text {st }}$ was blowing from the east, i.e. from the coast, turning to north-east from the $22^{\text {nd }}$ onwards. The temperature at the site for the most part of this period was between $10^{\circ} \mathrm{C}$ and $13{ }^{\circ} \mathrm{C}$.

During this five day period similar patterns start to appear as for the period described earlier. On several occasions, the leakage current activity intensifies as soon as the relative humidity exceeds $90 \%$ despite the absence of other weather effects. After the humidity drops lower than $90 \%$, the leakage current returns to its base value.

Furthermore, intense precipitation (up to $20 \mathrm{~mm} / \mathrm{h}$ ) starting on the afternoon of the $22^{\text {nd }}$ has a twofold effect. On one side, it causes the leakage current on the tension members to rise considerably. On the other hand, it reduces the leakage current activity for all the compression insulators. Milder intermittent rainfall at $10: 00$ and $12: 00$ of the $24^{\text {th }}$ causes the leakage current to oscillate, reducing initially and rising afterwards due to the high humidity level.

At 00:00 on the $25^{\text {th }}$ a combination of high humidity and the temperature dropping below $10{ }^{\circ} \mathrm{C}$ which lasts until the morning hours, results in condensation which in turn increases the leakage current on all insulators but especially on the ST member.

\section{DISCUSSION}

By looking at the leakage current patterns and weather conditions recorded during June 2012, the following observations can be made:

1) The base leakage current for all insulators has remained the same, indicating that no significant ageing has taken place.

2) The insulators closest to the conductor show higher base leakage current than the rest due to capacitive coupling between the conductor, the cross-arm members and the tower.

3) The leakage current on the south facing insulators is consistently higher than their west facing counterparts because the predominant wind (from the east) is perpendicular to their longitudinal axis. A bigger area exposed to the prevailing weather accelerates pollution accumulation.

4) There is a humidity threshold of approximately $90 \%$, which if exceeded, triggers leakage current activity on all insulators regardless of other weather conditions.

5) The compression members exhibit slightly higher base leakage current than the tension members directly above them. This can be attributed to their larger circumference. 
6) The tension members exhibit higher variations of leakage current than the compression members directly below them.

7) All insulators show self-cleaning properties. Their leakage current reduces even after minor periods of precipitation despite the fact that the leakage current on some of the tension insulators increases briefly when a prolonged dry period is followed by rainfall.

\section{CONCLUSIONS}

The first results from the live trial show that the insulating cross-arm performs according to design expectations. The leakage current patterns observed on the novel compression insulators are very similar to the ones observed on the industry standard tension insulators. Although the base leakage current profile of the compression members is marginally higher because of their bigger cross-section, their response to changes in the weather conditions is milder, with smaller fluctuations.

Further work is being undertaken in order to decouple the capacitive coupling effects and isolate the purely resistive component of the leakage current. This will ultimately normalise the leakage current values for all insulators regardless of their proximity to the conductor.

\section{ACKNOWLEDGMENTS}

The authors would like to acknowledge the support of Scottish and Southern Energy and National Grid, and Arago Technology for permission to publish.

\section{REFERENCES}

[1] K. Kopsidas, S. M. Rowland, M. N. R. Baharom, I. Cotton, "Power transfer capacity improvements of existing overhead line systems," International Symposium on Electrical Insulation (ISEI), 2010.

[2] C. Zachariades, S.M. Rowland, I. Cotton, P.R. Green, C.A. Veerappan and D.Chambers, "A Trial Installation of High Voltage Composite Cross-arms," XVII International Symposium on High Voltage Engineering (ISH), 2011.

[3] S.M. Rowland, Y. Xiong, J Robertson and S. Hoffmann, "Aging of silicone rubber composite insulators on $400 \mathrm{kV}$ transmission lines," IEEE Transactions on Dielectrics and Electrical Insulation, vol.14, pp.130-136, 2007.

[4] D. A. Swift, C. Spellman, A. Haddad, "Hydrophobicity transfer from silicone rubber to adhering pollutants and its effect on insulator performance," IEEE Transactions on Dielectrics and Electrical Insulation, vol.13, no.4, pp.820,829, 2006.

[5] G.G. Karady, "Flashover mechanism of non-ceramic insulators," IEEE Transactions on Dielectrics and Electrical Insulation, vol.6, no.5, pp.718-723, 1999.

[6] G. Montoya, I. Ramirez, R. Hernandez, "The leakage current as a diagnostic tool for outdoor insulation," Transmission and Distribution Conference and Exposition: Latin America, 2008 IEEE/PES , vol.1, no.4, pp.13-15, 2008.

[7] C. Zachariades, I. Cotton, S.M. Rowland, V. Peesapati, P.R. Green, D. Chambers, M. Queen, "A Coastal Trial Facility for High Voltage Composite Cross-arms," International Symposium on Electrical Insulation (ISEI), 2012. 